\title{
Barriers to pension scheme participation in small- and medium-sized enterprises
}

Recelved 18th October, 2004

\begin{abstract}
Alistair Byrne
is a lecturer in finance at the University of Strathclyde in Glasgow and a fellow of the Pensions Institute His research and consulting interests lie mainly in the application of behavioural economics to pension scheme design.
\end{abstract}

\section{Debbie Harrison}

is a senır visiting fellow of the Pensions Institute, a financial journalist, author and consultant She is a regular contributor to the Financial Times and author of the first undergraduate textbook on financial planning.

\section{David Blake}

is Professor of Pension Economics at Cass Business School in London and Director of the Pensions Institute, which he founded in 1996

\begin{abstract}
Large sections of the UK population are failing to make adequate provision for their retirement, and one area where provision is notably poor is among people working for small- and medium-sized businesses (SMEs). Information was gathered from interviews with individuals from a wide range of organisations active in the pensions market, for these companies to shed light on the particular barriers to pension scheme participation in this sector in which over 40 per cent of the working population is employed. It was found that many finance directors are sceptical of the benefits of providing pensions for their employees and deliberately structure their pension schemes to avoid high participation rates. It was also found that financial advisers and pension providers are reluctant to promote pensions in companies where they perceive the management to be unsupportive and where there is no clear profit margin. The authors suggest one way in which management could be motivated to encourage pension scheme participation among their employees.
\end{abstract}

Keywords: pensions; small- and medium-sized enterprises; participation rates; independent financial advisers; employee benefit consultants

Alistair Byrne

Department of Accounting and Finance,

University of Strathclyde,

100 Cathedral Street,

Glasgow, G4 OLN, UK

e-masl

alıstair byrne@strath ac.uk pensions@city acuk

\section{Introduction1}

Pension reform is firmly on the government's agenda, with significant legislative initiatives underway and, perhaps most significantly, the Pensions Commission conducting a comprehensive review of the sustainability of the UK pensions system. The Commission's recently published interim report contains a wealth of information and analysis on the extent to which large sections of the population are failing to make adequate provision for their retirement.

One area where provision is notably poor is amongst people working for small and medium sized businesses. which are defined as those with up to 250 employees and up to 1,000 
employees respectively. Together these companies employ over 40 per cent of the working population. This raises questions about whether there are particular barriers to pension scheme participation in this segment of the economy and, if so, what can be done to improve the situation. This paper attempts to shed some light on these issues using information gathered from interviews with individuals from a wide range of organisations active in the design and delivery of group pensions for these types of companies.

An important feature of this research is that it is based on interviews conducted on the understanding that the information provided and the opinions expressed would be quoted on a non-attributable basis. This methodology enables the authors to 'tell it how it is' rather than report the diluted attributable responses that would have emerged after interviewees had consulted their public relations, compliance, and legal departments. As such, the findings of this research are at times uncomfortable and controversial but it is hoped they will help explain what have hitherto been perceived as inexplicable gaps in information and understanding.

\section{Small- and medium-sized companies defined}

The research focuses on small and medium sized enterprises (SMEs) and the providers and advisers that service this vast and diverse market. There is no single definition of SME and in practice advisers to small and medium sized companies tend to identify potential clients in terms of both the number of employees and the earnings profile.

The definition of SMEs for the purposes of this research was, broadly speaking, those quoted companies below the FTSE 350 index - which denotes the unofficial market division for consultants, insurance companies and asset managers - and equivalently sized private companies and partnerships. In practice the 'solutions' offered to larger companies, particularly those presented by major consultants to the FTSE 100 companies, are simply not available to SMEs. As one such consultant succinctly explained: 'There's not enough money in it'.

The SME sector is, however, a very significant part of the overall economy. Office for National Statistics figures based on VAT-registrations show 410,000 enterprises employing between five and 249 people, representing a total of over 8 million employees, and a further 6,000 enterprises each with between 250 and 999 employees, totalling 3 million people. With approximately 24 million people employed in the UK, the market we are examining thus covers over 40 per cent of the total workforce. ${ }^{2}$

\section{Finance directors discourage high participation rates}

There has been a radical change in the way pension costs are perceived and managed by employers compared with ten and even five years ago. Few SMEs have a dedicated pensions department. Historically, the company pension scheme was regarded as a human resources function and was seen as part of the benefits package used to attract, retain and motivate staff, and also as a retirement management tool. Today, in many smaller companies in particular, the role of the finance director overndes that of the HR manager. Many finance directors regard pensions as a company cost rather than a company benefit.

Advisers to SMEs confirm that increasingly they find themselves dealing directly with the finance director. Given the cost and risk issues associated with 
the pension scheme, the managing director may also be part of the discussion, with HR playing a very secondary role.

'If we are talking to HR they will be very enthusiastic about the pension scheme. Finance directors tend to be lukewarm at best.' (IFA) To help the reader place comments in context we have indicated the type of organisation quoted as follows: EBC - employee benefits consultant; IFA - independent financial adviser; and $\mathrm{O}$ - other organisation, for example a regulatory, trade, professional or consumer body.

Advisers report that finance directors like defined contribution (DC) schemes because they have a quantifiable cost but that this explicit price tag makes pension participation in the workforce an easy target for cost analysis and containment. 'The reason we get the opportunity to carry out a review of existing schemes is that we tell the finance director we expect to be able to offer an alternative that will save the company money as well as improve value for members. It's the former rather than the latter that interests them.' (IFA)

Finance directors in SMEs regard cash flow and cost control as critical to the company's profitability. To help reduce the cost of pensions, in the majority of cases they expect the advisers to be remunerated by commission from the pension scheme provider. 'The finance director doesn't want to pay for advice and is more likely to be attracted to the commission-basis where the member bears the costs rather than pay a company fee.' (IFA)

Finance directors are also likely to restrict the amount of time the adviser is allowed to communicate the scheme to employees, as this takes staff away from their work. 'We explain we need at least three months to communicate to employees the closure of the old scheme, the start of the new scheme and all the complex issues that arise as a result. With defined benefit (DB) to DC transition we need five months because most employees do not understand their DB scheme in the first place. At the same time they see a change in their benefits as threatening. The finance director wants it all done in two weeks and expects a reduction in the cost if we reduce the communications process.' (EBC)

\section{Advisers screen potential clients very carefully}

Advisers in the SME market are often described by the major consultants as commission-driven salespeople - the implication being that they could go anywhere and sell anything.

In practice, it appears that advisers are very discerning in their selection of corporate clients and the attitude of the company's decision maker is a key issue. Clearly, it is in the adviser's best interests to sell to employers prepared to make a pension contribution for their employees and to support the communications process, although this is also true of the major employee benefit consultants in the FTSE 350 market.

'We find out very quickly about the benefits culture in the organisation. The pro-benefits conversations are likely to be with the HR manager, but in many of the companies we deal with HR doesn't have board representation. The HR manager reports to the finance director and so the finance director has the whip hand.' (IFA)

In selecting corporate clients, the age, financial sophistication, and average earnings level of the employees is also relevant to the potential for a high take-up, as is the company structure and location. Where there is commitment to pensions at head office (which translates 
into high participation rates in that location), this often fails to follow through to the company's other sites. Where a site operates its own payroll and profit and loss accounts, the employer's contribution will undermine performance unless it is given special recognition and separated from the payroll accounting.

\section{Finance directors want to see a return on investment}

It is important to recognise that the finance director is not opposed to costs per se, but to costs that do not deliver a measurable benefit to the company.

'Finance directors can be quite happy to spend money on a sick-leave management service - usually a helpline to deal confidentially with employees' concerns. This is because the provider can demonstrate a cut in the number of employee sick days and therefore can put a monetary value on the savings. But with the pension scheme it is impossible to demonstrate the return on investment. Studies that try to achieve this go so far and then collapse in a heap.' (EBC)

'It's impossible to prove to finance directors the cost benefits of the pension scheme. Unfortunately it is very easy to prove the opposite. If you ask employees whether they would like to have a pension scheme or would prefer an extra $5-10 \%$ of salary, they will always go for the cash in hand.' $(\mathrm{O})$

Employers that pay a pension contribution on behalf of those employees who are members of the pension scheme incur costs that increase directly in proportion with the number of employees who join the scheme. To give an example, for a company with 1,000 employees on national average (full time) earnings of $£ 25,000$ raising the participation rate from 30 per cent to 90 per cent would increase the cost of employer contributions from $\{375,000$

to $\mathcal{E} 1.1 \mathrm{~m}$ assuming an employer

contribution rate of 5 per cent of salary.

\section{One of the problems finance directors have with $\mathrm{DC}$ is that the cost is not flexible}

'The employer's contribution is not a flexible cost on a month by month basis but it is fixed. Smaller companies often have short-term cash flow problems but they know if they delay a pension contribution payment they will get into trouble with the Occupational Pensions Regulatory Authority (OPRA).' (EBC)

Advisers across the board say that with the employer's commitment they can achieve pension scheme participation rates of over 90 per cent. Many employers say that they do not want this level of take-up due to the cost.

If the finance director is unconvinced by the argument in favour of pension contributions, he or she is likely to impose strict limitations on the target participation rate. In this way, the finance director represents a very significant barrier to wider participation.

'We have to have a very serious discussion with the employer. We tell them that typically our worksite marketing proposition will take the participation rate from its current level of, say, $30 \%$, to over $90 \%$. Where there is an employer contribution this will have an immediate cost. We have to ask them how much they really want to pay.' (EBC)

'The employer needs to make it clear which sections of the workforce we should target. We have to be careful of anti-discrimination laws but we can vary the way we present from group to group.' (EBC)

'As an adviser we can lose a contract by being too successful.' (EBC)

The Department for Work and 
Pensions (DWP) is examining whether using automatic enrolment would increase pension scheme participation significantly and the government has suggested that it may be made compulsory where an employer pension contribution is on offer. Under this system all employees are automatically enrolled in the pension scheme but individuals can opt out if they do not wish to remain members. Several advisers already recommend automatic enrolment but report that few employers are keen to adopt the procedure.

'One of the easiest ways to secure a high take-up is to use automatic enrolment - so employees are in unless they make an active decision to opt out. Finance directors don't want this.' (IFA)

'No finance director is going to agree to automatic enrolment. If it becomes mandatory there are ways to ensure that it is quick, easy and attractive for the employees to opt out.' (IFA)

Another initiative the DWP is piloting is active decisions. This is where the employer gives employees a short and fixed period of time during which they must make a positive decision to join or decline membership. Employees are not allowed time to forget they have to make the decision or to make excuses by claiming they have lost the paperwork. Again, this practice is in use.

'Where we have the full support of $\mathrm{HR}$ and the company genuinely wants a high participation rate we can secure this by using active decision forms. These set out the benefits the employee is agreeing to forego. We make it sound important and that the decision has legal connotations. With the right wording it can be much easier and less worrying for the employee to sign a simplified enrolment form than to sign an agreement confirming their decision not to join. Unfortunately employers that let us take this approach are very rare.' (IFA)
Employers recognise that there are ways of making an apparently attractive scheme unappealing. The employee contribution level is a primary example.

'I was once asked to design a scheme that was very attractive from an $H R$ point of view, so that the HR team could promote the fact that they offered a great scheme, but at the same time I was asked to ensure that not everyone would join. The solution was to have quite a high employee contribution, which always acts as a barrier to participation.' (EBC)

Even among larger companies the commitment to the pension scheme can be questionable. As part of their image such companies like to be seen to be offering attractive pensions but in many cases this is as far as it goes.

'These days most employers recognise that all they have to do is to offer a pension scheme. In practice there can be a huge gap between making a scheme available and actually promoting it in an effective way' (EBC)

'In a lot of cases it would cripple a FTSE 350 company - let alone a smaller employer — if everyone joined the pension scheme. The true cost of $100 \%$ participation would be unaffordable.' (EBC)

\section{The employers must commit a combination of money and time}

In practice, participation rates are closely linked to the employer's, and in particular the finance director's, support and endorsement of the scheme. Advisers and providers require a strong commitment from the employer if they are to make a profit from the promotion and distribution of pensions in the workplace.

In this respect the objectives of the adviser and provider are aligned with those of the employees. For both parties 
we can identify employer commitment in terms of money and time as follows:

- The availability of an employer contribution (money). Without an employer contribution, advisers say they are not prepared to take on the client.

- The facility for learning about the scheme in group presentations, 'surgeries' (where employees can make an appointment to discuss an 1ssue) and one-to-one counselling sessions (time). Advisers report that employers vary considerably in terms of the time they are prepared to allow for staff to be away from their work.

As noted above, these valuable resources are unlikely to be forthcoming unless the employer perceives a return on them in the form of a more stable, motivated and productive workforce.

\section{Employers are not convinced of the return on pensions}

It is clear from this research that employers that appear to provide an attractive pension scheme in practice, can ensure low take-up through lack of endorsement, lack of time for communications and a high employee contribution rate. Empty stakeholder pension schemes are another, perhaps more visible, manifestation of this. Under the current voluntary system it is easy for employers to obey the letter of the law while 1gnormg its spirit.

The Trades Union Congress (TUC) has recently conducted research to find out how often employers referred to their pension contribution in job advertisements. The TUC expressed surprise at the general absence of this feature and wanted to know why it is that so many companies do not promote the employer pension contribution. ${ }^{3}$ The authors think this research goes some way towards answering the TUC's question.

Practitioners and the government must recognise that many employers no longer accept the traditional view that a generous pension scheme attracts, retains and motivates employees. If we retain a voluntary system of pensions provision, then employers will need to be provided with empirical evidence that high rates of pension scheme participation produce tangible benefits in terms of employee productivity and reduced workforce turnover costs. We do not know if it will be possible to produce unambiguous conclusions on this issue. ${ }^{+}$

\section{Anti-discrimination rules may motivate reluctant employers}

We are not convinced that if the government made automatic enrolment or active decisions mandatory that this would necessarily raise pension scheme participation in all cases. Sceptical employers can and will find ways around this, simply by manipulating the wording of the pension scheme forms or by imposing a high employee contribution rate as a deterrent.

The question, therefore, is how can the government promote increased participation rates in situations where the employer is unwilling? Compulsion is one answer: the government could simply require employers to pay pension contributions for their employees, but this approach does little to engage employees in the process.

A better solution might be to create incentives for the employer to encourage employees to join the pension scheme and to find a way to penalise them when they don't. In the USA 401(k) market this is done quite simply by restricting the amount of tax advantaged 
contributions that highly paid managers can pay into the pension scheme to a multiple of what the rest of the workforce contributes. If employees don't join the scheme, or contribute only at low rates, managers can find their own ability to contribute severely limited. (There are some 'safe harbour' provisions that allow companies to exempt themselves from these rules, one example being if they make an unconditional pension contribution for all employees of at least 3 per cent of salary.)

There is no real equivalent in the UK. Employers have to contribute at least 3 per cent of salary to a group personal pension (GPP) for each employee in order to avoid the requirement to designate a stakeholder pension for their employees, but the requirement of designation doesn't act as a sanction. The tax limits on pension contributions in the UK are high (and will get higher after April 2006) meaning high earners have substantial scope to provide for their retirement on a tax-advantaged basis. The introduction of some form of anti-discrimination rules could be an effective way of making sure those in the top levels of a company have a vested interest in raising participation throughout the workforce.

A number of US companies, 'motivated' by anti-discrimination rules, have used design mechanisms that exploit the findings from the field of behavioural economics to raise participation and contribution rates. These mechanisms recognise the importance of such psychological traits as inertia and lack of willpower. An increasingly commonly cited example is the Save More Tomorrow $^{\mathrm{TM}}$ scheme, whereby employees with a low savings rate commit in advance to allocate part of future pay rises to raising their pension contributions. ${ }^{5}$ Automatic enrolment is another example, but as previously noted this has to be used earnestly if it is to achieve higher participation rates.

The authors suspect that, given finance directors' interest in their own retirement planning, they might be more amenable to processes that overcome inertia in the main workforce if this is the only way they, and their senior colleagues, can avoid falling foul of anti-discrimination rules that will restrict the tax benefits they receive on their own pension contributions.

\section{Conclusions}

Pension problems are not exclusive to SMEs; far from it. The management and cost implications of pension provision for smaller and medium sized employers, however, are very different from those that affect larger companies. FTSE 350 employers - and equivalent private and foreign companies that are not listed on the London Stock Market - have a commercial reputation to maintain. They wish, and indeed need, to be seen as socially responsible employers. These companies have a very wide range of stakeholders and customers to consider. They are also likely to have a much broader choice of options and resources to enable them to withstand financial problems with $\mathrm{DB}$ schemes, and to be able afford to invest significantly in the promotion of their new DC pension schemes. Clearly these factors are recognised by the advisers and providers that operate in this lucrative segment of the market. At the same time, advisers and pension providers appear reluctant to devote much effort to promoting pensions in smaller companies, seeing little profit opportunity in it.

This unofficial market segmentation that limits pension scheme participation in smaller companies has serious implications for the government's pensions policy. We suggest that if the 
Barriers to pension scheme participation in small- and medium-sized enterprises

divide cannot be breached, for reasons of commerce and profit, then at the very least it should be explicit and publicly debated, so that policymakers keen to increase pension participation among SMEs can develop workable solutions with the organisations that actually operate in this market.

In the light of these findings, the government must understand that if no changes are made to the way company-sponsored pensions are delivered in the small- and medium-sized business market it will not succeed in significantly extending pension provision and has virtually no chance of achieving its ambition to change the 40:60, private/state benefit dependency ratio, to $60: 40$ by the year 2050 . The evidence suggests that the government has not recognised where the real barriers to participation lie for smaller companies, and that it does not consider seriously the views of advisers that work in, and understand, this tough market.

\section{References}

1 This paper is based on more detalled research published in the Pensions Institute Practitioner Report - 'Delivenng DC? Barriers to participation in the company-sponsored pensions market'. The full report can be purchased from www.pensions-institute.org.

2 Source: Office for National Statistics.

3 TUC press release dated 17th August, 2004.

4 Momentum, now part of Origen, included some interesting but limited data on pension scheme design and employee turnover in its '2004/5 Employee Benefits Survey' Tel: 01252557404.

5 Bernartzı, S and Thaler, R (2004) 'Save more tomorrow: Using behavioural economics to increase employee saving' Joumal of Political Economy, Vol 312, No. 1, pp S164-S187. 